\title{
Brief from Drug Advisory Programme, the Colombo Plan
}

\section{Background}

Despite the availability of international research journals on substance abuse, there is a distinct gap between what is being reported by the research experts and the transfer of this into practice. Research processes and outcomes are not always readily transferred to the day to day working context of the practitioner. Similarly, reports of quality practice, with relevance for researchers and practitioners are uncommon. Moreover, it says 'Science is meaningless unless the lessons learnt from it are communicated'. 'Demand reduction', prevention was the least-researched area, although most countries considered it to be a national priority. ${ }^{2}$

Recognising the large gaps persisting among the policy, practices and research in the substance use disorders, the Colombo Plan has taken a lead in advancing the linkages among research and practice by producing an international journal. Thus this journal will be available and accessible to both scientific community and drug demand reduction practitioners such as drug treatment counsellors, recovering persons and treatment coordinators.

The experts are of the view that the dissemination of research findings in the drugs field, as in science in general, should be mainly achieved through the publication of articles in peer- reviewed journals. ${ }^{3}$ Complimenting these arguments, this journal will provide a forum for the Colombo Plan to advance the scientific literature by engaging a broad global network of scholars and researchers in the field who could advance the understanding of drug treatment and prevention technologies, and their application throughout the world.

The Colombo Plan is partnering with the National Rehabilitation Center (NRC) in this endeavour, as it compliments NRC's overall objective; to advance the science in drug field, provide a venue for the cutting edge research across a wide range of approaches and topics.

International Journal of prevention and treatment of Substance Use Disorders (IJPTSUD) is an open access, peer-reviewed international journal by the Colombo Plan Drug Advisory Programme which is produced in collaboration with the NRC, Abu Dhabi. The journal is devoted to publishing original work related to the prevention and treatment of substance use disorders, through a transparent and rigorous peer review process. The journal offers authors high visibility for their papers through its various networks, and member governments, access to a broad readership including an Arabic edition and high standards of copy editing and production. The journal aims to maintain a strict peer review system and a rapid editorial procedure to ensure high quality submission. Manuscripts which are not published elsewhere will be considered for publication. 